\title{
Penerapan Penghalusan Savitzky-Golay pada Pengukuran Konsentrasi Etilen dengan Detektor Fotoakustik
}

\author{
Ign Edi Santosa \\ Pendidikan Fisika, Universitas Sanata Dharma \\ Paingan, Maguwohardjo, Depok Sleman, Yogyakarta \\ Email: edi@dosen.usd.ac.id
}

\begin{abstract}
Abstrak
Telah dilakukan pengukuran konsentrasi etilen dari biocream yang dikenai paparan sinar ultraviolet. Pengukuran dilakukan dengan detektor fotoakustik. Untuk mengurangi efek derau, telah dilakukan penghalusan dengan metoda Savitzky-Golay. Hasil penghalusan tergantung pada orde polinomialnyadan jumlah titik data untuk fiting.
\end{abstract}

Kata kunci: fotoakustik, smoothing, Savitzky Golay

\begin{abstract}
In this study ethylene released during $U V$ irradiation on the biocream has been investigated using a laser-based photoacoustic detector. Savitzky-Golay smoothing filter has been used to reduce the random variation. The smoothing depends on the degree of polynomial and the number of points to be fitted
\end{abstract}

Key words: photoacoustic detector, smoothing filter, Savitzky-Golay 


\section{PENDAHULUAN}

Salah satu faktor yang perlu diperhatikan dalam suatu pengukuran adalah keberadaan derau. Untuk itu derau perlu dihilangkan atau dikurangi. Berbagai macam metoda pengurangan derau telah dikenal secara luas, antara lain perbaikan perancangan alat, perbaikan metoda pengukuran dan cara menganalisa data. Perancangan alat dilakukan untuk mengurangi derau dapat dilakukan dengan metoda "inherent" tidak sensitif terhadap derau, metoda umpan balik berpenguatan tinggi, penggunaan lock-in amplifier dan lainnya [Doebelin, 1990]. Metoda pengukuran juga dikembangkan untuk mengurangi efek dari derau, misalnya dengan melakukan pengulangan pengukuran secara signifikan. Selain itu dengan analisa data yang sesuai efek dari derau juga dapat dikurangi.

Detektor fotoakustik merupakan detektor yang bekerja berdasar pada konversi tenaga cahaya menjadi bunyi. Sistim peralatan ini telah dirancang agar derau sangat kecil. Berkat eliminasi derau ini pengukuran konsentrasi dengan detektor fotoakustik dapat sangat sensitif. Detektor ini banyak digunakan di berbagai bidang seperti untuk pengukuran konsentrasi etilen dari kulit yang terkena paparan sinar ultraviolet [Harren et al., 1999; Cristescu et al., 2000]. Meskipun demikian banyak faktor yang masih perlu diperhatikan. Ketersediaan daya laser sangat mempengaruhi pembangkitan sinyal. Sehingga nilai nisbah sinyal terhadap noise $(\mathrm{S} / \mathrm{N})$ juga dipengaruhi oleh daya laser.

Dalam keadaan sinyal yang rendah, pengaruh derau sangat dominan. Meskipun peralatan telah dirancang dengan baik, derau dapat menutupi sinyal. Dalam situasi demikian dapat dilakukan "penghalusan". Berbagai metoda "penghalusan" sinyal telah dikenal antara lain "averaging", Fourier Transform (FFT) dan Savitzky-Golay [Grissom dan Koehler, 1971; Marchand dan Marmet, 1983; Press dan Teukolsky, 1990; Levesque, 2008]. Pada makalah ini digunakan penghalusan Savitzky-Golay untuk mendapatkan nilai konsentrasi etilen dari cream yang terpapar sinar ultraviolet.

\section{TEORI}

\section{II.1. Detektor Fotoakustik}

Detektor fotoakustik memiliki tiga komponen utama yaitu sumber cahaya misalnya laser, sel fotoakustik dan pengolah data. Bila molekul yang ada di dalam sel fotoakustik menyerap cahaya yang masuk ke dalam sel fotoakustik, maka akan terjadi proses eksitasi. Proses ini dapat disusul dengan deeksitasi secara non radiasi, yaitu ketika tejadi tumbukan, tenaga eksitasinya ditransfer menjadi tenaga tranlasi molekul lain yang ditumbuknya. Sebagai akibatnya akan terjadi kenaikan suhu dan juga tekanan di dalam sel fotoakustik. Bila lasernya dimodulasi maka tekanan di dalam sel fotoakustik akan berubah secara periodik yang dapat ditangkap dengan mikrofon [Zharov dan Letokhov, 1986]. Keluaran dari mikrofon tergantung pada daya laser, koefisien serapan dan konsentrasi gas. Jika di dalam sel fotoakustik hanya terdapat satu macam gas " $\mathrm{g}$ ", hubungan antara keluaran mikrofon dan besaran-besaran di muka dinyatakan dalam persamaan (1) di bawah ini

$$
\mathrm{S}_{l}=\mathrm{CP}_{l} \mathrm{C}_{\mathrm{g}} \alpha_{\mathrm{g} l}
$$

dengan $S_{1}$ adalah sinyal keluaran mikrofon sewaktu digunakan laser dengan panjang gelombang tertentu (pada garis laser " $l$ ") dengan daya $\mathrm{P}_{l}, \mathrm{C}$ adalah konstanta sel fotoakustik, $\mathrm{C}_{\mathrm{g}}$ 
adalah konsentrasi gas "g" dalam sel fotoakustik dan $\alpha_{\mathrm{g} l}$ adalah koefisien serapan dari gas "g" pada garis laser "l". Jika di dalam sel fotoakustik terdapat lebih dari satu jenis gas, masing-masing gas akan memberikan sumbangan pada sinyal keluaran mikrofon. Sebagai akibatnya sinyal ternormalisasi dengan dengan daya laser total akan mengikuti persamaan (2) di bawah

$$
(\mathrm{S} / \mathrm{P})_{1}=\sum_{\mathrm{g}}^{\mathrm{G}}(\mathrm{S} / \mathrm{P})_{1}=\mathrm{C} \sum_{\mathrm{g}}^{\mathrm{G}} \mathrm{C}_{\mathrm{g}} \alpha_{\mathrm{gl}}
$$

dengan $\mathrm{G}$ adalah cacah komponen gas yang ada di dalam sel fotoakustik

Untuk menentukan konsentrasi masing-masing komponen gas, laser ditala pada beberapa panjang gelombang (beberapa garis laser). Pada setiap garis laser "l" sinyal keluaran mikrofon mengikuti persamaan (2) di atas, sehingga kita akan mendapatkan satu set persamaan linear (3). Bila konstanta sel fotoakustik dan koefisien serapan masing-masing gas pada setiap garis laser "l" $\left(\alpha_{\mathrm{gl}}\right)$ diketahui, dengan menggunakan persamaan (3) di bawah, konsentrasi masing-masing komponen gas $\left(\mathrm{C}_{\mathrm{g}}\right)$ dapat ditentukan dengan mengukur sinyal keluaran mikrofon ternormalisir.

$$
\begin{aligned}
& (\mathrm{S} / \mathrm{P})_{\mathrm{l}=1}=\sum_{\mathrm{g}}^{\mathrm{G}}(\mathrm{S} / \mathrm{P})_{\mathrm{l}=1}=\mathrm{C} \sum_{\mathrm{g}}^{\mathrm{G}} \mathrm{C}_{\mathrm{g}} \alpha_{\mathrm{g} 1} \\
& (\mathrm{~S} / \mathrm{P})_{\mathrm{l}=2}=\sum_{\mathrm{g}}^{\mathrm{G}}(\mathrm{S} / \mathrm{P})_{\mathrm{l}=2}=\mathrm{C} \sum_{\mathrm{g}}^{\mathrm{G}} \mathrm{C}_{\mathrm{g}} \alpha_{\mathrm{g} 2}
\end{aligned}
$$

\section{II.2. Savitzky-Golay Smoothing}

Akibat adanya derau yang acak, dapat menimbulkan fluktuasi data. Untuk mengurangi distorsi, efek variasi acak ini perlu diperhalus. Penghalusan ini berdasar pada fitting data dengan metoda kuadrat terkecil [Grissom dan Koehler, 1971; Press dan Teukolsky, 1990].

Misal suatu ekperimen menghasilkan satu set data diskrit $\left\{\mathrm{f}_{\mathrm{i}}\right\}$ fungsi dari satu set nilai diskrit $\left\{\mathrm{x}_{\mathrm{i}}\right\}$. Untuk mengurangi distorsi pada hasil tersebut akan ditentukan set baru $\left\{\mathrm{F}_{\mathrm{i}}\right\}$ yang lebih halus. Set tersebut dibangkitkan dengan cara dari $\left\{\mathrm{f}_{\mathrm{i}}\right\}$ dipilih $\mathrm{f}_{\mathrm{k}}$ dan sejumlah $\mathrm{m}$ buah nilai lain di sebelah-menyebelah $f_{k}$. Dengan demikian diperoleh $2 \mathrm{~m}+1$ buah titik. Kemudian titik-titik tersebut difit dengan polinomial orde $n$

$$
y=a_{0}+a_{1} x+\cdots+a_{n} x^{n}
$$

Dengan menggunakan kriteria metoda kuadrat terkecil akan didapat koefisien $a_{n}$. Dengan ditemukannya koefisien tersebut selanjutnya diperoleh hasil penghalusannya yaitu nilai $F_{k}$ untuk setiap $\mathrm{x}_{\mathrm{k}}$ mengikuti

$$
F_{k}=a_{0}+a_{1} x_{k}+\cdots+a_{n} x_{k}^{n}
$$

\section{EKSPERIMEN}

Peralatan yang digunakan dalam eksperimen disajikan pada gambar 1 . Laser yang digunakan sebagai sumber cahaya terdiri dari cermin (2), tabung discharge (6) dan kisi (8). Laser ini dimodulasi dengan sebuah chopper (7) dan diukur dayanya dengan power meter (1). Sinyal fotoakustik akan dihasilkan di dalam sel fotoakustik (3) dan ditangkap dengan sebuah mikrofon (4). Sinyal ini selanjutnya akan direkam dan diolah dengan Lock-in amplifier dan computer. Biocream yang ditempatkan di tempat sampel (9) disinari dengan sinar ultraviolet yang dipancarkan oleh lampu UV (10). Hasil proses ini akan dialirkan menuju sel fotoakustik melalui inlet (5). 


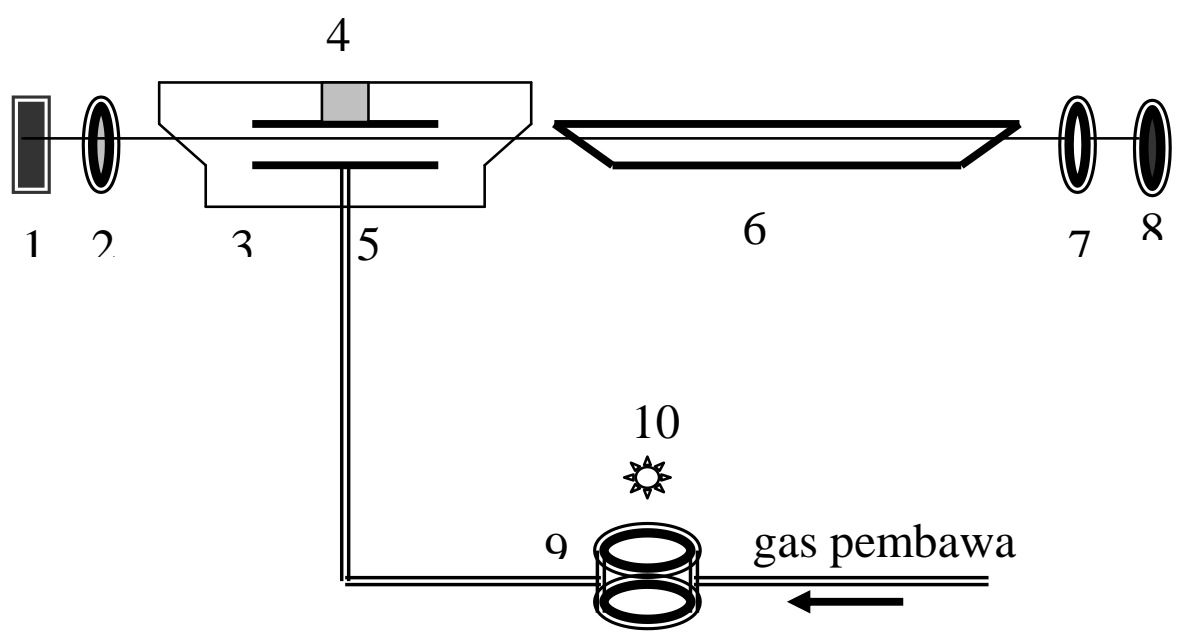

Gambar 1. Susunan peralatan sistim fotoakustik dengan laser CO2.

1. Power meter; 2. Cermin; 3. Sel fotoakustik; 4. Mikrofon; 5. Inlet sampel gas; 6. Tabung discharge; 7. Chopper; 8. Kisi; 9. Tempat sampel; 10 Lampu UV

IV. HASIL EKSPERIMEN DAN PEMBAHASAN

Akibat penyinaran sinar ultraviolet, kulit akan mengalami proses lipid peroksidasi dan salah satu akibatnya menghasilkan gas etilen [Harren et al., 1999; Cristescu et al., 2000]. Hal ini terjadi karena membran sel kulit terdiri dari lipid. Pada percobaan ini biocream yang digunakan juga mengandung lipid, sehingga akan menghasilkan etilen ketika disinari dengan sinar ultravolet. Hal ini ditunjukkan pada gambar 2. Dari gambar tampak bahwa etilen mulai dipancarkan ketika sinar ultraviolet dinyalakan, dan pancaran etilen hilang ketika lampu dimatikan.

Selama pemaparan intensitas sinar ultravioletnya tidak berubah, namun tampak bahwa hasilnya berfluktuasi. Faktor yang mempengaruhi fluktuasi ini antara lain derau dan cara menghitungnya.

Penghitungan konsentrasi ini menggunakan dua garis laser mengikuti persamaan (3). Pengukuran di kedua garis laser tersebut tidak bersamaan tetapi secara bergantian. Sehingga kalau ada salah satu hasil yang tidak sesuai maka pnghitungannya juga akan kurang tepat.

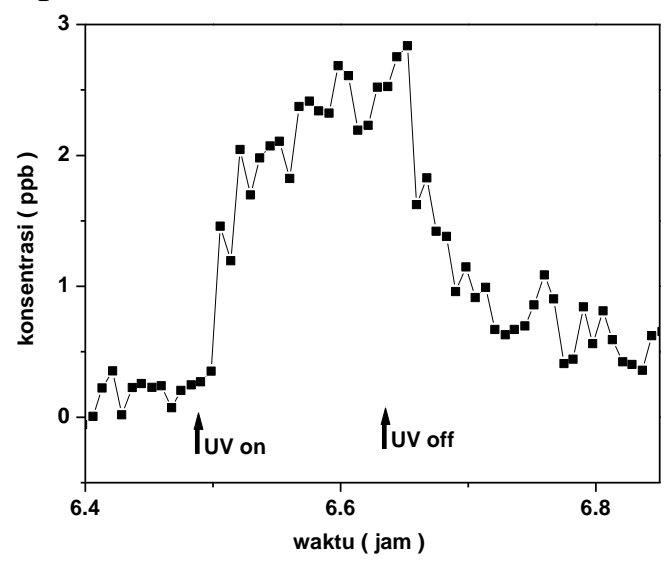

Gambar 2. Hasil pengukuran konsentrasi etilen dari cream yang disinari dengan sinar ultraviolet.

$\begin{array}{ccr}\text { Untuk } & \text { itu } & \text { dilakukan } \\ \text { "penghalusan" } & \text { dengan } & \text { metoda } \\ \text { Savitzky-Golay } & \text { seperti } & \text { yang }\end{array}$ ditunjukkan pada gambar 3, 4, 5 dan 6 . Hasil penghalusan ini menggunakan software Microcal Origin 6. Pada gambar tersebut hasil penghalusan dibandingkan dengan hasil eksperimennya di satu tempat. Agar lebih jelas, hasilnya digeser ke atas, agar tidak berimpit. 


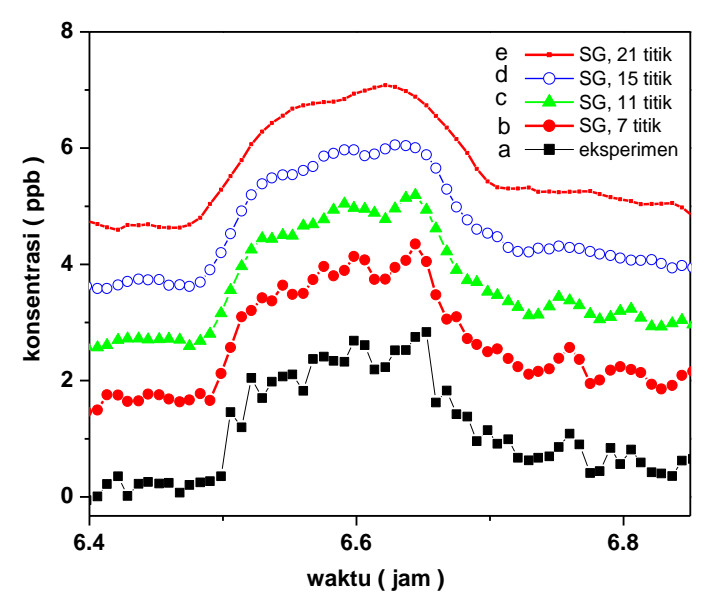

Gambar 3 Hasil penghalusan menggunakan Savitzky-Golay dengan polinomial orde 4 untuk berbagai jumlah titik. Untuk memperjelas perbandingannya, gambar hasil penghalusan ini digeser ke atas: a. hasil eksperimen; b. untuk 7 titik; c. untuk 11 titik; d. untuk 15 titik; e. untuk 21 titik.



Gambar 4. Hasil penghalusan menggunakan Savitzky-Golay dengan polinomial orde 6 untuk berbagai jumlah titik. Untuk memperjelas perbandingannya, gambar hasil penghalusan ini digeser ke atas: a. hasil eksperimen; b. untuk 7 titik; c. untuk 11 titik; d. untuk 15 titik; e. untuk 21 titik.

Pada metoda penghalusan ini yang mempengaruhi adalah jumlah titik yang digunakan untuk difit, dan orde polinomial hasil fiting tersebut. Gambar 3 menunjukkan hasil penghalusan untuk polinomial orde 4, dengan jumlah titik untuk fiting datanya bervariasi yaitu 7 titik (kurva b), 11 titik (kurva c), 15 titik (kurva d) dan 21 titik (kurva e). Dari gambar tersebut tampak bahwa semakin banyak titik yang digunakan untuk fiting hasilnya semakin halus. Namun dapat menimbulkan masalah karena pola data eksperimennya menjadi kurang terlihat. Hal ini disebabkan jangkauan titik yang difit terlalu lebar.

Hasil yang sama terlihat pada gambar 4 yang menunjukkan hasil penghalusan untuk polinomial orde 6, dengan jumlah titik untuk fiting datanya bervariasi yaitu 7 titik (kurva b), 11 titik (kurva c), 15 titik (kurva d) dan 21 titik (kurva e).

Untuk fiting dengan jumlah titik data yang sama ditunjukkan pada gambar 5 dan 6. Gambar 5 menunjukkan hasil penghalusan dengan 11 buah titik untuk fiting datanya. Sedang hasil penghalusan untuk berbagai orde polinomial ditunjukkan pada kurva b (orde 2), kurva c (orde 4) dan kurva d (orde 6). Hasil penghalusan untuk 21 buah titik pada berbagai orde polinomial ditunjukkan pada gambar 6 .

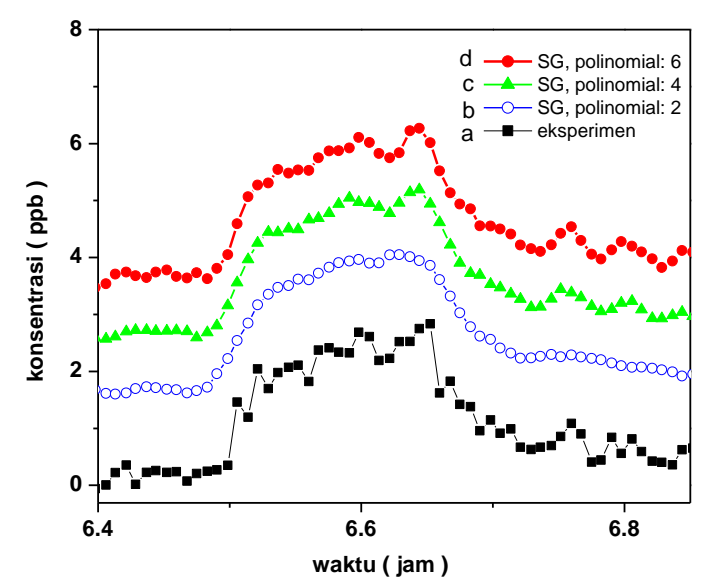

Gambar 5 Hasil penghalusan menggunakan Savitzky-Golay dengan 11 titik untuk berbagai. Untuk memperjelas perbandingannya, gambar hasil pengahalusan ini digeser ke atas: a. hasil eksperimen; b. untuk polinomial orde 2; c. untuk polinomial orde $4 ; \mathrm{d}$. untuk polinomial orde 6 . 


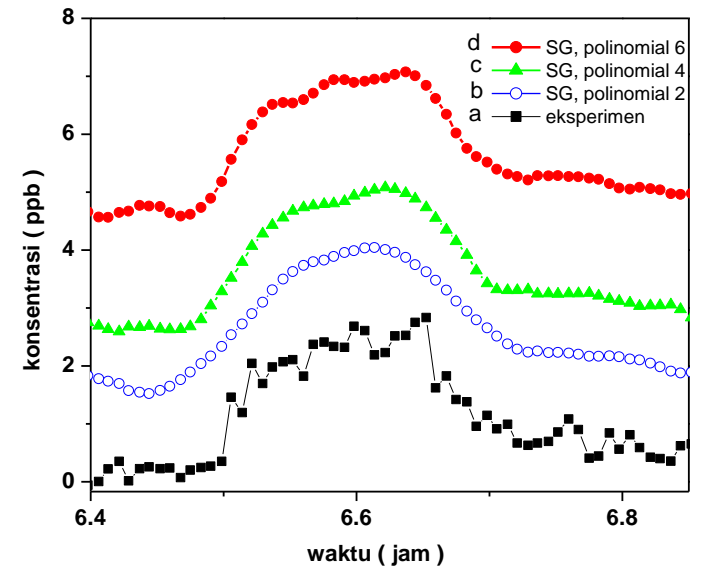

Gambar 6. Hasil penghalusan menggunakan Savitzky-Golay dengan 21 titik untuk berbagai. Untuk memperjelas perbandingannya, gambar hasil pengahalusan ini digeser ke atas: a. hasil eksperimen; b. untuk polinomial orde 2; c. untuk polinomial orde 4; d. untuk polinomial orde 6 .

Dari gambar 5 dan 6 tampak bahwa untuk orde polinomial yang rendah, hasilnya halus namun pola keseluruhan yang dihasilkan tampak berbeda dari hasil eksperimen. Sebaliknya semakin tinggi orde polinomialnya, hasil penghalusannya masih memperlihatkan ciri hasil eksperimen. Puncak tertentu masih tampak meskipun secara keseluruhan juga terlihat halus. Hal ini dikarenakan hasilnya akan lebih banyak memenuhi titik-titik data yang difit.

Salah satu kendala dalam proses penghalusan semacam ini adalah tidak ada kriteria baku untuk membatasi jumlah titik yang difit maupun orde polinomialnya [Grissom dan Koehler, 1971. Sehingga untuk jangkau tertentu kondisinya sesuai sedang yang lain tidak terpenuhi. Untuk hasil eksperimen di atas pancaran etilen mengikuti keberadaan sinar ultraviolet. Karena selama penyinaran, intensitasnya tetap, maka diperkirakan pancarannya juga stabil. Salah satu hasil penghalusan yang sesuai dapat ditunjukkan pada gambar 3 (kurva d) yaitu untuk polinomial orde 4 dengan 15 titik. Sedangkan hasil seperti pada gambar 6 (kurva b), untuk 21 titik dengan polinomial orde 2 kurang sesuai. Untuk itu informasi / keterangan tentang seluk beluk eksperimen sangat diperlukan untuk menentukan hasil yang sesuai.

\section{KESIMPULAN}

Metoda penghalusan Savitzky -Golay dapat digunakan untuk mengurangi distorsi hasil eksperimen karena gejala acak dan derau. Pemilihan paramater untuk penghalusan ditentukan oleh keadaan eksperimennya.

\section{Daftar Pustaka}

1. Cristescu, S., Berkelmans, R., te Lintel Hekkert, S., Timmerman, B., Parker, D., Harren, F. "Photoacoustic trace gas detection of ethene released by UV-induced lipid peroxidation in humans", Proc of SPIE, Vol 4162, 101 (2000).

2. Doebelin, E. O. "Measurement System Application and Design". New York: McGraw Hill. (1990).

3. Grissom, J.T., Kohler, D.R. "Data Smoothing". Am. J. Phys 39, 1314 (1971).

4. Harren, F. J. M.., Berkelmans, R., Kuiper, K., te Lintel Hekkert, S., Scheepers, P., Dekhuijzen, R., Hollander, P., Parker, D. H. "Online laser photoacoustic detection of ethene in exhaled air as biomarker of ultraviolet radiation damage of the human skin". Appl Phys Lett, 74(12), 1761 (1999).

5. Levesque, L. "Simple smoothing technique to reduce data scattering in physics experiments". Eur. J. Phys.229, 155 (2008). 
6. Marchand, P., Marmet, L. "Binomial smoothing filter: A way to avoid some pitfails of least -squares polynomial smoothing". Rev. Sci. Instrum, 54 (8), 1034 (1983).

7. Press, W.H., Teukolsky, S.A. "Savitzky-Golay

Smoothing
Fiters". Computer in Physics 4, 669 (1990).

8. Zharov, V.P., Letokhov, V.S. "Laser Optoacoustic Spectroscopy, Springer Series in Optical Science 37”. Berlin. Springer-Verlag, (1986). 